\title{
Vitamin D: enough already?
}

\section{Vitamina D: JÁ temos O SUficiente?}

\author{
ARNALDO LICHTENSTEIN ${ }^{1}$
}

We are at a historic moment in relation to vitamin $\mathrm{D}$, and researchers are divided into two groups. Believers who think we should supplement it orally for almost the entire population, similar to what is done with fluoride added to water, iodine added to salt and folic acid prescribed for all pregnant women. On the other hand, skeptics think there is a possible exaggeration, as seen in the past with the widespread use of hormone replacement or prolonged use of bisphosphonates.

History shows real examples of great successes and big mistakes with such positions.

The vitamins industry has a turnover in the United States of 28 billion dollars annually. There has been a growth in sales, from $30 \%$ in 1988-1994 to $39 \%$ in the years 2003-2006; consumption also increased from 42 to $53 \%$ of the population. Regarding only supplements containing vitamin $\mathrm{D}$, sales rose from 50 million dollars in 2005 to 600 million dollars in 2011.

All this in spite of robust data that supplementation of vitamins in non-malnourished people does not prevent deaths, cardiovascular disease, cancer and cognitive decline. In addition, antioxidants such as betacarotene, vitamin $\mathrm{E}$ and possibly higher doses of vitamin actually increase mortality. Supplementation of folic acid and B complex has no benefit either, when done indiscriminately. All these data were part of an editorial in the Annals of Internal Medicine in 2013, entitled Enough is Enough, giving an end to the waste of money. ${ }^{1}$ Nevertheless, in this article the authors warn that, in the case of vitamin D, studies on prevention of falls could be useful.

I also remember the controversy generated by the winner of two Nobel prizes Linus Pauling, who advocated the consumption of large doses of vitamin $\mathrm{C}$ routinely.

Knowledge of rickets comes from the early Christian era, with Sorano of Ephesus and Galen, who proposed breastfeeding up to 2 to 3 years of age (prohibiting colostrum). In 1650, rickets started to be treated with cod liver oil by Francis Glisson, a professor from the University of Cambridge. ${ }^{2}$
In England, Edward Mellanby, in experiments with dogs, also found that cod liver oil reversed rickets. This inspired Elmer Mc Collum to describe, in 1922, vitamin $\mathrm{D}$ (which he initially thought was vitamin A).

German pediatrician Kurt Huldschinsky found that rickets could be cured with ultraviolet rays, even before the discovery of vitamin D. There was no sun in Berlin at that time. Harry Goldblat and Miss K. M. Soames published in 1922 the relationship between ultraviolet rays and vitamin $\mathrm{D}$.

Vitamin D was isolated in Germany by Windaus, who was awarded the Nobel Prize, and also by British, Dutch and American scientists.

The extra-skeletal actions of vitamin $\mathrm{D}$ are known for over a century. Initially, it was used to treat tuberculosis (then, phtisis). In 1848, at the Royal Brompton Hospital, English physicians conducted a controlled study for tuberculosis. 542 patients received cod oil $(3.6 \mathrm{~mL}$, three times/ day, increasing to $42 \mathrm{~mL} /$ dose) versus 535 who did not. In the end, $33 \%$ of patients in the control group had worsened or died, compared with 19\% in the treated group. In the treated group, increase in weight was seen in $70 \%$ of patients, while $21 \%$ lost weight and $7 \%$ remained the same. Weight was not assessed in the control group. Keep in mind that Koch's bacillus was isolated in 1892, the first radiographs were made in 1895, and statistical analyzes appeared in 1922 (Fisher). This study certainly would not be accepted today. Interestingly, the author who reviewed the study says that at that hospital, in the 1960s, all the doctors would prescribe cod liver oil routinely, without knowing why. ${ }^{3}$

Biological plausibility cannot justify its use. ${ }^{4}$ Over 3,000 binding sites for vitamin D have been identified in the human body, in approximately $3 \%$ of all genes. For decades, we have used clinical evidence, rather than theoretical possibilities or personal opinions, to recommend a treatment.

How to explain the great disparity between the results of observational studies (where there is a clear relationship between low levels of vitamin D and the studied event) and interventional studies (vitamin D supplementation does not reduce the studied event)? $?^{5-8}$ 
For believers, the justification is that meta-analyzes are based on studies with vitamin D supplementation using various doses and duration. They believe that we would have to give high doses for a long time to achieve the effect. For skeptics, it is a matter of reverse bias, that is, patients are ill and, therefore, have low levels of vitamin $\mathrm{D}$, it not being the cause of the event studied.

Vitamin D dosage adds flavor to the discussion: if there is a high probability of having low pre-test levels, why should we measure it? It is known that $70 \%$ of the US population has levels below normal.

For the American Society of Endocrinologists, vitamin D levels should "only" be measured in risk groups (chronic use of medication [anticonvulsants, corticosteroids, antiretrovirals and antifungal], pregnant women and infants, African-Americans and Hispanics, obese and elderly individuals with a history of falls and non-traumatic fractures, osteoporosis, malabsorption and granulomatous diseases. It also recommends that dosage for cases of rickets, chronic kidney disease, and liver disease. ${ }^{9}$ Which means most people).

For the United States Preventive Service Task Force (USPSTF, one of the main advisors for health promotion), supplementation would help prevent falls in the elderly, and this should be done indiscriminately, without serum measurements. ${ }^{10}$

What to do when the levels are below normal is also controversial.

First, cutoff values for serum 25(OH)D3 have not been defined for incidence or prevalence of health problems in population groups. They were calculated from the simple correlation with serum concentrations of parathyroid hormone (PTH). In other words, levels of 25(OH)D3 below $20 \mathrm{ng} / \mathrm{mL}$ (divider between insufficiency and vitamin $\mathrm{D}$ deficiency, according to most of the criteria adopted $)^{11}$ trigger elevation of PTH levels above the established as normal (intermediate outcome), but do not necessarily represent higher risks of appearance of non-bone disease (final outcome). In addition, there is a wide variation in seasons and latitude of the study population. Thus, it is very difficult to know the normal level of vitamin $\mathrm{D} 3$. The question is: normal values, when and where?
Thus, the natural tendency, but not necessarily right, is to correct an altered level, which would result in overtreatment.

In the midst of such fascinating scenario, some paths can be traced. Observational studies are no longer necessary, but a large prospective study to define the levels of vitamin D3/parathyroid hormone before the outcome, then correct them and re-evaluate the outcome.

For the management of a patient, there is no reason to measure vitamin D3 levels if the intention is to supplement it. Use it in reasonable doses, no more than 2000 $\mathrm{UI} /$ day, always keeping in mind the implications of industrializing sunbathing.

\section{References}

1. Guallar E, Stranges S, Mulrow C, Appel LJ, Miller III ER. Enough is enough: stop wasting money on vitamin and mineral supplements. Ann Intern Med. 2013; 159(12):850-1.

2. Silva JM. Breve história do raquitismo e da descoberta da vitamina D. Acta Reum Port. 2007; 32:205-29.

3. Green M. Cod liver oil and tuberculosis. BMJ 2011; 343:d7505.

4. Lichtenstein A, Ferreira-Júnior M, Sales MM, Aguiar FB, Fonseca LAM, Sumita NM, et al. Vitamina D: ações extraósseas e uso racional. Rev Assoc Med Bras. 2013; 59(5):495-506.

5. Beveridge LA, Struthers AD, Khan F, Jorde R, Scragg R, Macdonald HM, et al. Effect of vitamin D supplementation on blood pressure: a systematic review and meta-analysis incorporating individual patient data. JAMA Intern Med. 2015; 175(5):745-54.

6. Chowdhury R, Kunutsor S, Vitezova A, Oliver-William C, Chowdhury S, Kiefte-de-Jong JC, et al. Vitamin D and risk of cause specific death: systematic review and meta-analysis of observational cohort and randomised intervention studies. BMJ. 2014; 348:g1903

7. Autier P, Boniol M, Pizot C, Mullie P. Vitamin D status and ill health: a systematic review. Lancet Diabetes Endocrinol. 2014; 2(1):76-89.

8. Theodoratou E, Tzoulaki I, Zgaga L, Ioannidis JPA. Vitamin D and multiple health outcomes: umbrella review of systematic reviews and meta-analyses of observational studies and randomised trials. BMJ. 2014; 348:g2035.

9. Holick MF, Binkley NC, Bischoff-Ferrari HA, Gordon GM, Hanley DA, Heaney RP, et al. Evaluation, treatment, and prevention of Vitamin D deficiency: an Endocrine Society Clinical Practice Guideline. J Clin Endocrinol Metab. 2011; 96(7):1911-30

10. LeBlanc E, Chou R, Zakher B, Daeges M, Pappas M. Screening for vitamin D deficiency: systematic review for the U.S. Preventive Services Task Force Recommendation. Evidence Synthesis No. 119. AHRQ Publication No. 1305183-EF-1. Rockville: Agency for Healthcare Research and Quality, 2014.

11. Ross AC, Taylor CL, Yaktine AL, Del Valle HB (eds.). Committee to Review Dietary Reference Intakes for Vitamin D and Calcium. Institute of Medicine; 2011. Available at: http://www.nap.edu/catalog.php?record id=13050. 